\title{
Preparation of Tumor-Specific Magnetoliposomes and Their Application for Hyperthermia
}

\author{
BIAO LE ${ }^{1}$, MASASHIGE SHINKAI ${ }^{1}$, \\ TAMOTSU KITADE ${ }^{1}$, HIROYUKI HONDA ${ }^{1}$, \\ JUN YOSHIDA ${ }^{2}$, TOSHIHIKO WAKABAYASHI ${ }^{2}$ \\ AND TAKESHI KOBAYASHI ${ }^{1}$ \\ ${ }^{1}$ Department of Biotechnology, Graduate School of Engineering, \\ Nagoya University, Nagoya 464-8603, Japan \\ ${ }^{2}$ Department of Neurosurgery, Graduate School of Medicine, \\ Nagoya University, Nagoya 466-8550, Japan
}

Keywords: Hyperthermia Therapy, Magnetic Particle, Drug Delivery, Antibody, Immobilization

\begin{abstract}
Magnetoliposomes (MLs) were conjugated with an antibody fragment to give specificity to a tumor. The antibody fragment was cross-linked to $N$-(6-maleimidocaproyloxy)-dipalmitoyl phosphatidylethanolamine (EMC-DPPE) in liposomal membrane. The immobilization of the antibody fragment was optimal when the content of EMC-DPPE was 10-wt \% and the reaction time for immobilization was $18 \mathrm{~h}$. The Fab' fragment-conjugating MLs (FMLs) were 2.4 times higher molar immobilization density compared with the method using the whole antibody. The targetability of the FMLs to the glioma cells, U251-SP, was then investigated. The amount of FMLs uptake reached $85 \mathrm{pg} / \mathrm{cell}$ in an in vitro experiment using plastic dishes. In an in vivo experiment using glioma-harboring mice, $260 \mu \mathrm{g}$ of the FMLs per $1 \mathrm{~g}$ of tumor tissue accumulated (tumor sizes was $0.1 \mathrm{~cm}^{3}$ ), which corresponded to approximately $60 \%$ of the total injection. This value was 7 times higher than that of the MLs. After injection of the FMLs, mice were exposed to intracellular hyperthermia using the alternating magnetic field irradiation. The temperature of tumor tissue increased to $43^{\circ} \mathrm{C}$ and the growth of the tumor was found to be arrested over 2 weeks. These results indicate the FMLs could target the glioma cells in vitro and in vivo, and are efficiently applicable to the hyperthermia of tumor.
\end{abstract}

\section{Introduction}

Hyperthermia is a therapy based on the fact that tumor cells are more sensitive to temperature in the range of $42-45^{\circ} \mathrm{C}$ than normal tissue cells (Cavaliere et al., 1967; Overgaard and Overgaard, 1972; Overgaard, 1977). Unlike chemotherapy and radiotherapy, hyperthermia itself has few side effects. Various methods have been reported to achieve cancer hyperthermia (Lyons et al., 1984; Hiraoka et al., 1994). However, almost all of these methods heat not only the tumor, but also normal tissue, in which animal bodies tested will be damaged by nonspecific heating. Therefore, a new method which can heat only a desirable area and new heating mediator for this idea are needed. A few researchers have been investigating submicron magnetic particles as the heating mediator (Tazawa et al., 1986; Jordan et al., 1993; Chan et al., 1993; Shinkai et al., 1994a). If magnetic particles can be accumulated only in the tumor tissue, they can generate heat by hysteresis loss under a high frequency

Received on July 11, 2000. Correspondence concerning this article should be addressed to T. Kobayashi (E-mail address: takeshi@nubio.nagoya-u.ac.jp). magnetic field and cancer specific heating is available.

We have developed "magnetite cationic liposomes (MCLs)" as a "magnetoliposomes (MLs)" containing cationic lipid (Shinkai et al., 1996). MCLs show ten times higher affinity for glioma cells than that of the MLs with neutral charge, because of the positive charge on the surface. It has been proven that the high affinity of magnetite to the cells allows complete killing of tumors (Yanase et al., 1997, 1998a). However, its cationic charge causes adsorption in normal cells. Therefore, administration of MCLs is limited to a direct injection into the tumor tissue. From this background, a novel magnetic particle, which can adsorb to only target cells, should be developed.

Conjugation of antibodies to the magnetic particles is one of the strong candidates to achieve the aim mentioned above. We have developed "antibody-conjugated magnetoliposomes" (Shinkai et al., 1994b) and an antibody-conjugated polyethylene oxide-magnetite complex (Suzuki et al., 1996). However insufficient accumulation of magnetite particles to tumor tissue was a serious problem, because it resulted in insufficient heating in the cases of small tumor tissue. In the present paper, we developed unique antibody-conjugated MLs with high affinity and high heating ability, and inves- 
tigated their affinity to glioma cells in vitro and in vivo. Moreover, their hyperthermia effect was demonstrated using mouse subcutaneous tumor.

\section{Materials and Methods}

\subsection{Reagents}

The magnetite particles were prepared by the nitrite oxidation method as reported previously (Shinkai et al., 1994b). Phosphatidylcholine (PC) was purchased from Wako Pure Chemicals Co. (Osaka, Japan) and phosphatidylethanolamine (PE) from Tokyo Chemical Industry Co. (Tokyo, Japan). Dipalmitoyl phosphatidylethanolamine (DPPE), N-succinimidyl-3-(2pyridyldithio)propionate (SPDP) and pepsin (1:10000, porcine stomach mucosa) were purchased from Sigma Chemicals Co. (St. Louis, MO). N-(6-maleimidocaproyloxy)succinimide (EMCS) was from Dojin Laboratories Co. (Kumamoto, Japan). All other chemicals were purchased from Wako Pure Chemicals.

\subsection{Cells and antibodies}

A human glioma cell line U251-SP was maintained at $37^{\circ} \mathrm{C}$ in a $5 \% \mathrm{CO}_{2}$ atmosphere in Eagle's minimum essential medium (Gibco BRL, Gaithersburg, MD) supplemented with $10 \%$ fetal bovine serum, $5 \mathrm{mM}$ nonessential amino acids, and antibiotics (100 U/ml penicillin $\mathrm{G}$, and $100 \mu \mathrm{g} / \mathrm{ml}$ streptomycin). The $\mathrm{G} 22$ monoclonal antibody (IgG type I) and its $\mathrm{F}\left(\mathrm{ab}^{\prime}\right)_{2}$, fragment, which specifically binds to the antigen of many gliomas cell lines containing U251-SP, was provided by Dr. J. Yoshida of Nagoya University (Yoshida et al., 1987). Sheep anti-mouse IgG antibody and its $\mathrm{F}\left(\mathrm{ab}^{\prime}\right)_{2}$ fragment were from Organon Teknika (Westchester, U.K.) and mouse monoclonal IgG (type I) as a control antigen for anti-mouse $\mathrm{IgG}$ antibody and non-specific antibody against U251-SP was from Bethyl Laboratories Inc. (Montgomery, TX, U.S.A.).

1.3 Synthesis of $N$-(6-maleimidocaproyloxy)dipalmitoyl phosphatidylethanolamine (EMCDPPE)

The EMC-DPPE was synthesized as follows. DPPE (34.5 mg, $49.9 \mathrm{mmol}$ ) and EMCS (32.5 mg, 105 $\mathrm{mmol})$ dissolved in chloroform $(2.5 \mathrm{ml})$ containing triethylamine $(5 \mathrm{mg})$ were reacted at $60^{\circ} \mathrm{C}$ for $10 \mathrm{~h}$. The reaction mixture was applied to $10 \mathrm{ml}$ silica gel column, which had been activated $\left(150^{\circ} \mathrm{C}\right.$, overnight before use), and then the column was washed with chloroform. In the first step, free DPPE fraction was removed with chloroform-methanol mixtures (20:1, v/ v). Then, the EMC-DPPE was eluted in chloroformmethanol mixtures $(5: 1, \mathrm{v} / \mathrm{v})$. The eluent containing the EMC-DPPE was concentrated under reduced pressure. The resultant EMC-DPPE was dissolved in chloroform and stored at $-20^{\circ} \mathrm{C}$ after nitrogen purge.

\subsection{Preparation of antibody fragments}

SPDP (in a small proportion of methanol) was added in the antibody solution $(1 \mathrm{mg} / \mathrm{ml}, 0.1 \mathrm{M}$ so-

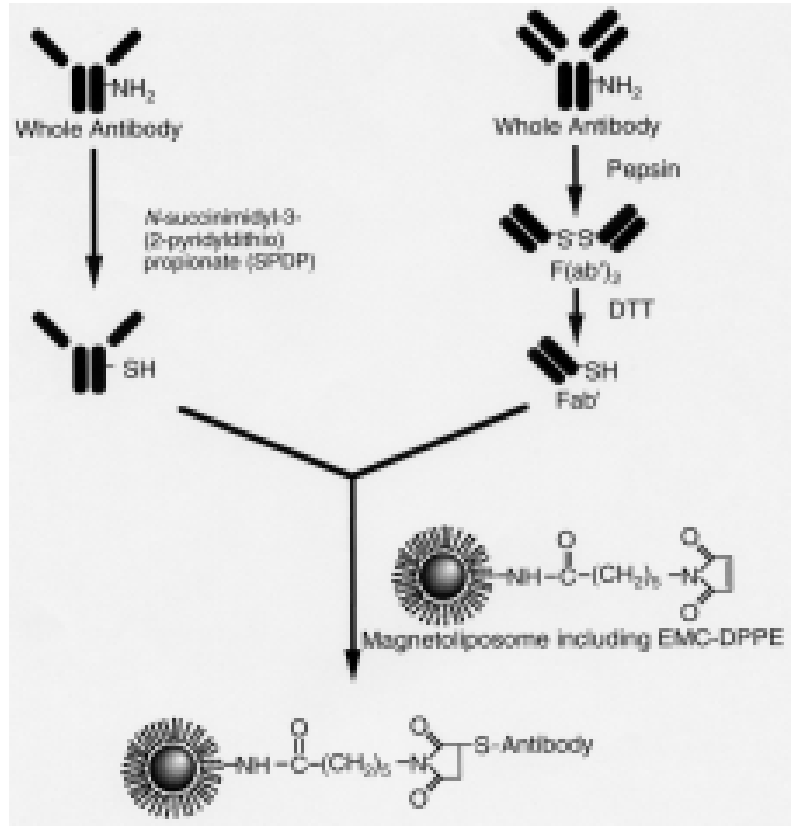

Fig. 1 Scheme of two immobilization methods of antibody to magnetoliposomes

dium phosphate buffer containing $0.15 \mathrm{M} \mathrm{NaCl}$, pH 7.5) at a molar ratio 50:1-8:1, and the mixture was reacted for $30 \mathrm{~min}$ at room temperature. Unreacted SPDP was removed by gel filtration with $0.1 \mathrm{M}$ acetate buffer containing $0.15 \mathrm{M} \mathrm{NaCl}$ (pH 5.0). SPDPmodified antibody was reduced with 1,4-dithiothreitol (25 mM) after nitrogen purge, $0.1 \mathrm{M}$ acetate buffer, pH 5.0, for $90 \mathrm{~min}$ at room temperature. 1,4Dithiothreitol was removed by gel filtration with 0.1 $\mathrm{M}$ sodium phosphate buffer containing $5 \mathrm{mM}$ EDTA (pH 6.0).

$\mathrm{F}\left(\mathrm{ab}^{\prime}\right)_{2}$ fragments were prepared by pepsin digestion of the whole antibody. The whole antibody $(1 \mathrm{mg} /$ $\mathrm{ml})$ was incubated with pepsin $(5 \mathrm{mg} / \mathrm{ml})$ in $0.1 \mathrm{M}$ sodium citrate buffer ( $\mathrm{pH} \mathrm{3.8)}$ for $12-15 \mathrm{~h}$ at $37^{\circ} \mathrm{C}$. Digestion was terminated by adding $3 \mathrm{M}$ Tris ( $\mathrm{pH} 8.0$ ) to a final concentration of $80 \mathrm{mM}$, then centrifuging $\left(10000 \times \mathrm{g}, 30 \mathrm{~min}, 4^{\circ} \mathrm{C}\right)$. The supernatant was dialyzed with $0.1 \mathrm{M}$ acetate buffer ( $\mathrm{pH}$ 5.0) for the following step. $\mathrm{F}\left(\mathrm{ab}^{\prime}\right)$, fragments $(1 \mathrm{mg} / \mathrm{ml})$ were reduced with $0.1 \mathrm{M}$ acetate buffer containing $25 \mathrm{mM}$ 1,4-dithiothreitol ( $\mathrm{pH} \mathrm{5.0)}$ ) for $90 \mathrm{~min}$ at room temperature to obtain the Fab' fragment. Then, dithiothreitol was removed by gel filtration (Econopack 10DG column, BioRad, Hercules, HA) with $0.1 \mathrm{M}$ sodium phosphate buffer containing $5 \mathrm{mM}$ EDTA ( $\mathrm{pH}$ 6.0).

\subsection{Immobilization of antibodies on MLs}

A procedure for preparation of the whole antibodyconjugating magnetoliposomes (AbMLs) is shown in Fig. 1. The MLs were prepared by our previous method (Shinkai et al., 1994b). An adequate amount of EMCDPPE was added in the step of the preparation of phos- 
pholipid membrane in the bottom of a round flask. The reduced whole antibody $(0-200 \mathrm{mg} / \mathrm{ml})$ was added in MLs (net magnetite concentration: $1 \mathrm{mg} / \mathrm{ml}$ ) and incubated for $20 \mathrm{~h}$ at $4^{\circ} \mathrm{C}$ in sodium phosphate buffer (containing 5 mM EDTA, pH 6.0). The resultant AbMLs and free antibody were separated by centrifugation at $13000 \times \mathrm{g}$ for $30 \mathrm{~min}$. The amount of immobilized antibody was estimated from the differences of the antibody concentration in the reaction mixture before and after the immobilization. Antibody concentration was determined by protein assay (BCA Protein Assay Reagent, Pierce, Rockford, Ill). The Fab' fragments of the antibody and of the non-specific antibody were conjugated with MLs in the same way (FMLs and NS-FMLs, respectively).

\subsection{Binding activity assay}

To assess the binding activity of the antibody immobilized on the AbMLs or FMLs, sheep anti-mouse IgG was immobilized to the MLs. The $70 \mathrm{mg}$ of mouse IgG was added to the AbMLs or FMLs (net magnetite: $1 \mathrm{mg}$ ) and incubated for $4 \mathrm{~h}$ at room temperature. The bound mouse IgG and free mouse IgG were separated by centrifugation $(12000 \times \mathrm{g}, 30 \mathrm{~min})$. The amount of mouse IgG was determined by measuring the difference in the protein concentration before and after the antigen-antibody reaction by using the protein assay.

\subsection{FMLs uptake by tumor cells in vitro}

U251-SP cells were used as model tumor cells and the uptake of FMLs were investigated. U251-SP cells $\left(2 \times 10^{5}\right.$ cells $\left./ \mathrm{ml}\right)$ were cultivated in $35 \mathrm{~mm}$ tissue culture dish with $2 \mathrm{ml}$ of the medium. After $24 \mathrm{~h}$, the medium was replaced with G22-FMLs, NS-FMLs or MLs containing the medium (net magnetite: $100 \mathrm{pg}$ / cell) and incubated at $37^{\circ} \mathrm{C}$, under gentle shaking by a reciprocating shaker (SHK-320, Asahi Techno Glass Co., Tokyo, $70 \mathrm{rpm}$ ). After incubation for 1, 4 or $8 \mathrm{~h}$, the cells were washed with $1 \mathrm{ml}$ PBS twice and harvested by a rubber policeman. The quantity of adsorbed magnetite was measured by our previous method (Shinkai et al., 1996).

\subsection{Preparation of tumor-bearing nude mouse}

The U251-SP cells were subcutaneously transplanted in the femur of female 4-week-old KSN-nu/nu nude mice. A tumor tissue obtained from nude mice was cut into pieces of about $2 \mathrm{~mm}$ in diameter and the piece was used for transplantation of another mouse. The transplanted tumors had grown to $1 \mathrm{~cm}$ in diameter, approximately 3 weeks after transplantation. Tumor sizes were measured every 2 or 3 days. The volume was determined by the following formula (Yoshida et al., 1991):

$$
\text { Tumor volume }=0.5 \times\left(\text { length } \times \text { width }^{2}\right)
$$

where the units of length and width are centimeters.

\subsection{FMLs uptake by tumor cells in vivo}

$0.1 \mathrm{ml} \mathrm{G} 22-F M L s$ or NS-FMLs (net magnetite: 5 $\mathrm{mg} / \mathrm{ml}$ ) were injected into tumors with a needle (needle size: $25 \mathrm{G}, 1.2 \mathrm{ml} / \mathrm{h}$ ) using an infusion pump (SP100i, World Precision Instruments Inc., Sarasota, FL, U.S.A.). At $24 \mathrm{~h}$ after injection, the mouse was sacrificed and the tumor and organ were removed from the mouse. The quantity of adsorbed magnetite was measured by our previous method (Yanase et al., 1998a).

\subsection{In vivo hyperthermia}

When ellipsoidal tumor tissue had grown to $1 \mathrm{~cm}$ in diameter, $0.1 \mathrm{ml} \mathrm{G} 22-F M L s$ (net magnetite: $5 \mathrm{mg}$ / $\mathrm{ml}$ ) were injected at the center of the tumor. At $24 \mathrm{~h}$ after the injection, the mice were anesthetized and subjected to the magnetic field which was created by using a horizontal coil (inner diameter: $7 \mathrm{~cm}$; length: 7 $\mathrm{cm})$ with a transistor inverter (LTG-100-05, $(5.0 \mathrm{~kW}$, 118 kHz); Dai-Ichi High Frequency Co. Ltd., Tokyo). Anesthetized mice were laid inside the coil such that the tumor region was at the center. The magnetic field frequency and intensity were $118 \mathrm{kHz}$ and $30.6 \mathrm{kA} / \mathrm{m}$ (384 Oe), respectively. The heat evolution rate of all types of MLs used in the present paper was $96 \mathrm{~W} / \mathrm{g}$ at this condition. Treatment was carried out for $30 \mathrm{~min}$ and repeated three times at 24-h intervals. An optical fiber probe (FX-9020; Anritsu Meter Co. Ltd., Tokyo) measured temperatures with the tumor surface and rectum. The temperature at the surface of the tumor was lower than that in the inner part where the magnetite existed when the mice was irradiated with the magnetic field. Therefore, we measured the surface temperature of the tumor to evaluate the feasibility of this hyperthermia.

Animal experiments were performed according to the principles laid down in the "Guide for the Care and Use of Laboratory Animals" prepared under the directions of the Office of the Prime Minister of Japan.

\section{Results and Discussion}

\subsection{Optimal preparation of antibody-conjugated magnetoliposomes}

In order to conjugate antibody to the magnetoliposomes, the method using whole antibody (AbMLs) and the method using Fab' fragment (FMLs) were compared (Table 1). Here, anti mouse IgG from sheep was used as the antibody. The immobilization density of FMLs was a little bit lower than that of AbMLs. However, FMLs provided 2.4-fold higher immobilization density ( $626 \mathrm{pmol} / \mathrm{mg}$ magnetite) than AbMLs (258 pmol/mg of magnetite) on a molar basis, since the molecular weight of the Fab' fragment (M.W. $46,000)$ is one third of the whole antibody (M.W. 150,000). Therefore, in the case of AbMLs, steric hin- 
Table 1 Immobilization density and antigen binding activity of antibody after immobilization

\begin{tabular}{lcc}
\hline & FMLs & AbMLs \\
\hline $\begin{array}{l}\text { Immobilization density } \\
\text { [ } \mu \text { g of antibody/mg magnetite] }\end{array}$ & 31.3 & 40.0 \\
$\begin{array}{l}\text { Molar immobilization density } \\
\text { [pmol of antibody/mg magnetite] }\end{array}$ & 626 & 258 \\
$\begin{array}{l}\text { Antigen binding activity } \\
\text { [pmol of protein/mg magnetite] }\end{array}$ & 79.0 & 18.1 \\
\hline
\end{tabular}

Used antibody: Anti mouse IgG from sheep Antigen: Mouse IgG

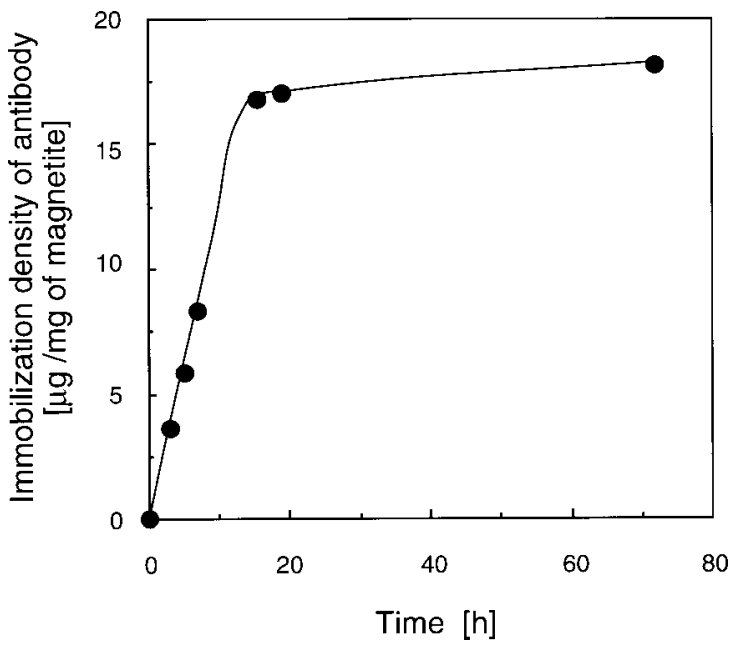

Fig. 2 Time course of immobilization density of antibody to MLs. Added Fab' fragments: $70 \mathrm{mg} /$ mg magnetite, EMC-DPPE content: $5 \%$ in liposomal membrane

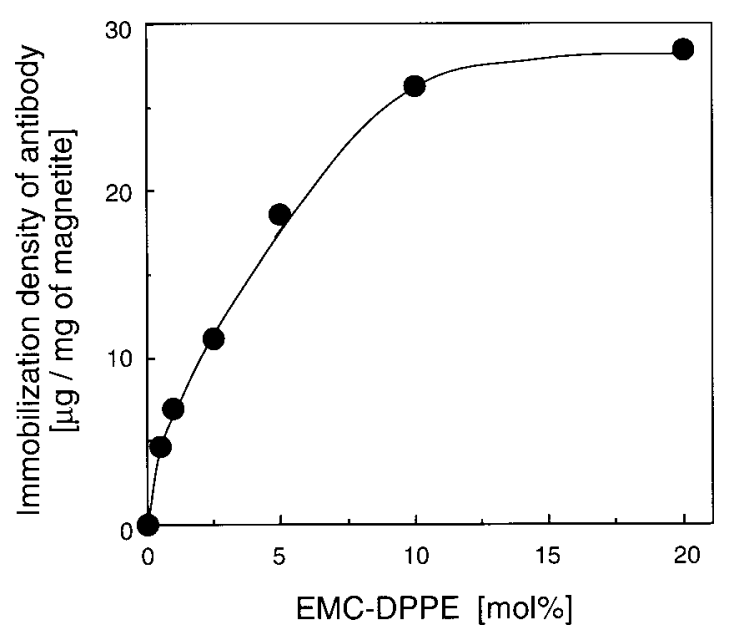

Fig. 3 Variation of immobilization density against EMCDPPE content in liposomal membrane. Immobilization time was $18 \mathrm{~h}$. Added Fab' fragments: 70 $\mathrm{mg} / \mathrm{mg}$ magnetite

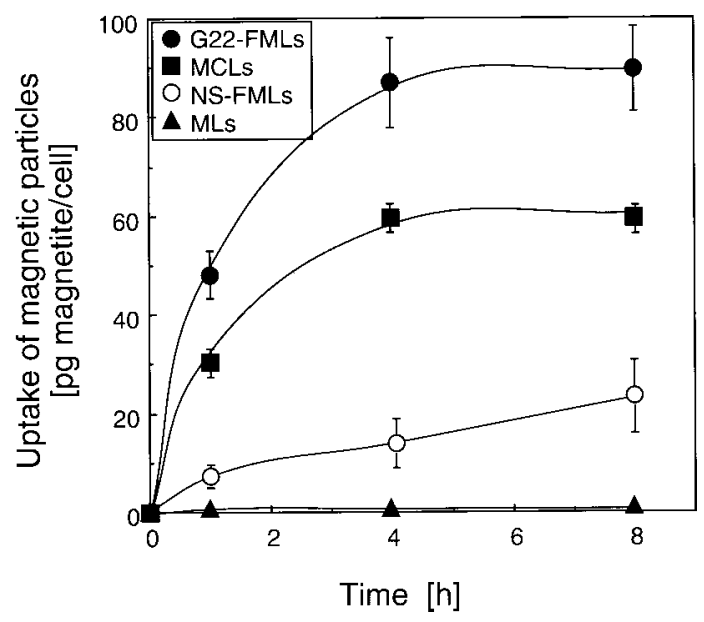

Fig. 4 Time courses of magnetite uptake by U251SP cells in vitro. Data points and bars are means and SDs of 5 independent experiments. Refer to each abbreviation in text

drance of the antibody seems to decrease its immobilization density. When mouse IgG was used as an antigen, the antigen binding activity $(79 \mathrm{pmol} / \mathrm{mg}$ of magnetite) of FMLs was 4 times higher than that (18.1 $\mathrm{pmol} / \mathrm{mg}$ of magnetite) of AbMLs. A higher activity of FMLs is due to a lower steric hindrance of the Fab' fragment than that of the whole antibody. Therefore, FMLs were used further in the following experiments.

Next, optimization for the immobilization of the Fab' fragment was studied. The time course of the immobilization of the Fab' fragment to MLs is shown in Fig. 2. The amount of the Fab' fragment conjugation reached $17 \mu \mathrm{g} / \mathrm{mg}$ magnetite after $18 \mathrm{~h}$, and did not increase further when the initial concentration of the $\mathrm{Fab}^{\prime}$ fragment was $70 \mu \mathrm{g} / \mathrm{mg}$-magnetite. On the other hand, the effect of EMC-DPPE molar ratio on the immobilization of the Fab' fragment to MLs are shown in Fig. 3. The immobilization density increased with the increase of the EMC-DPPE concentration from 0 to $10 \mathrm{~mol} \%$ and did not show an obvious increase when the concentration of EMC-DPPE was above $10 \mathrm{~mol} \%$. From these results, the EMC-DPPE concentration of $10 \mathrm{~mol} \%$ with the immobilization time of $18 \mathrm{~h}$ was chosen to be optimal to the conjugation of the Fab' fragment to the MLs.

\subsection{In vitro uptake of antibody-conjugated magnetoliposomes by tumor cells}

From this experiment, the G22 antibody was used instead of anti mouse $\operatorname{IgG}$ from sheep. The uptake of G22-FMLs by tumor cells in vitro is shown in Fig. 4. The G22-FMLs were quickly incorporated in U251SP cells, and the maximum amount of uptake was 85 $\mathrm{pg} /$ cell after $4 \mathrm{~h}$. This value was 100 times higher than that of the MLs, and 5 times higher than that of the NS-FMLs. In addition, the present value was about 20 times higher than that of our previous method (Shinkai 


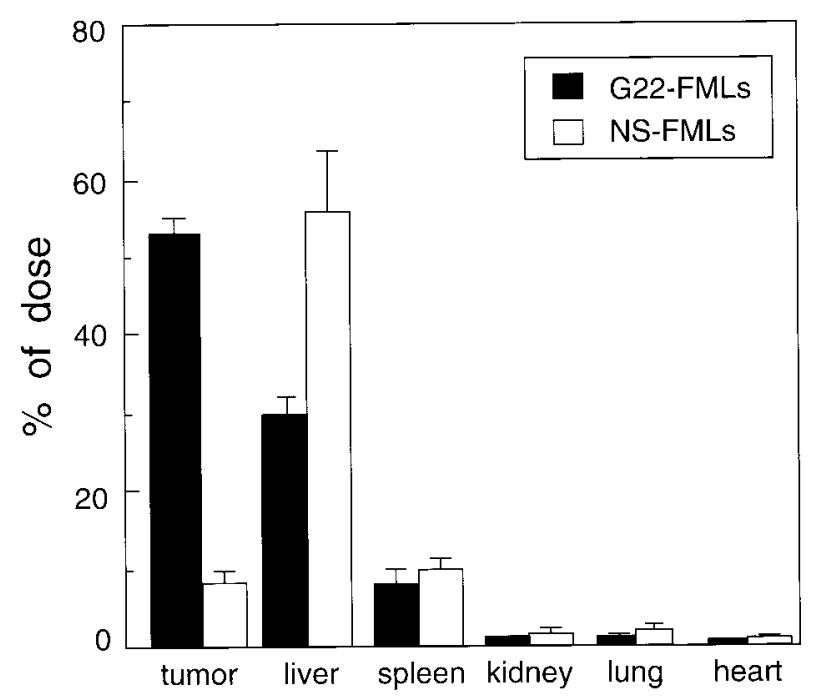

Fig. 5 Magnetite uptake by tumor and various organs. Data and bars are means and SDs of 5 independent experiments. Refer to each abbreviation in the text

et al., 1994b), because the immobilization density in the present method was 5 times higher than that in the previous method. In contrast with NS-FMLs, G22FMLs achieved a high adsorption ratio through the interaction of G22 monoclonal antibody with U251-SP. The MLs showed very low adsorption since there was no interaction of phospholipid membrane between the cell surface and the liposomes. On the other hand, the uptake of G22-FMLs was 1.5 times higher than that of the MCLs. The amount of MCL uptake was sufficient to heat tumor as shown in our previous results (Shinkai et al., 1996). It means the G22-FMLs can heat tumors better than the MCLs, and they can heat tumors more specifically than the MCLs.

\subsection{In vivo uptake of antibody-conjugated magnetoliposomes by tumor cells \\ The uptake of G22-FMLs was investigated in an} in vivo experiment (Fig. 5). The G22-FMLs (260 mg) were found to accumulate in the tumor. This amount corresponded to $53 \%$ of the total injected amount, and its value was approximately seven times higher than that of the NS-FMLs. Injected NS-FMLs diffused in the tumor tissue, and were removed from the tumor by blood flow. On the other hand, the G22-FMLs adsorbed on the tumor cell surface by the antigen-antibody reaction, and the G22-FMLs remained in the tumor tissue. In the case of the MLs, the maximum adsorption ratio of the magnetite was $58 \%$ in the liver, which was two times higher than that of the G22-FMLs. The accumulation of G22-FMLs in the other organs was almost the same as that of the NS-FMLs. This means that almost all of the NS-FMLs removed from the tumor by blood flow were trapped by Kupffer cells in the liver.

Figure 6 shows the section of tumors in which the G22-FMLs (A) or the NS-FMLs (B) were injected.
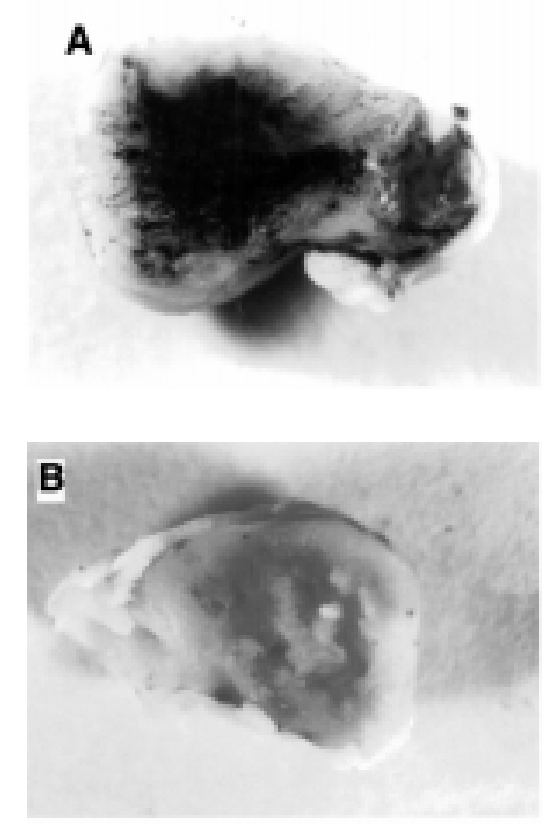

Fig. 6 Photographs of tumor specimens at $24 \mathrm{~h}$ after injection. A: G22-FMLs, B: NS-FMLs

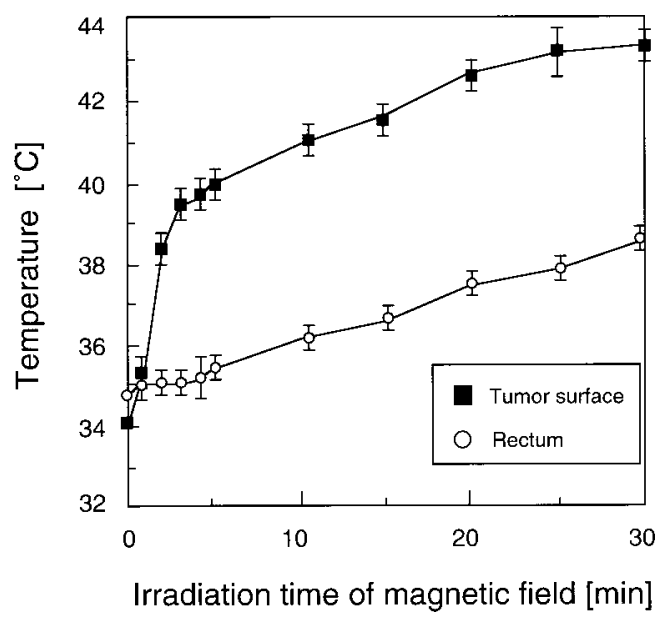

Fig. 7 Temperature increase at tumor surface and in rectum during magnetic field irradiation. Data points and bars are means and SDs of 5 independent experiments

The magnetite is shown as black regions in the specimens. As shown in the above results, the G22-FMLs are shown to have a high specific target ability for the glioma cells in vitro and in vivo.

\subsection{Hyperthermia}

Irradiation of the alternative magnetic field heats only magnetic particles in this experiment. Almost all G22-FMLs accumulated in the tumor tissue as shown in Fig. 5. Therefore, the temperature of the tumor surface was elevated rapidly by the irradiation of the magnetic field and reached $40^{\circ} \mathrm{C}$ after $5 \mathrm{~min}$ as shown in 


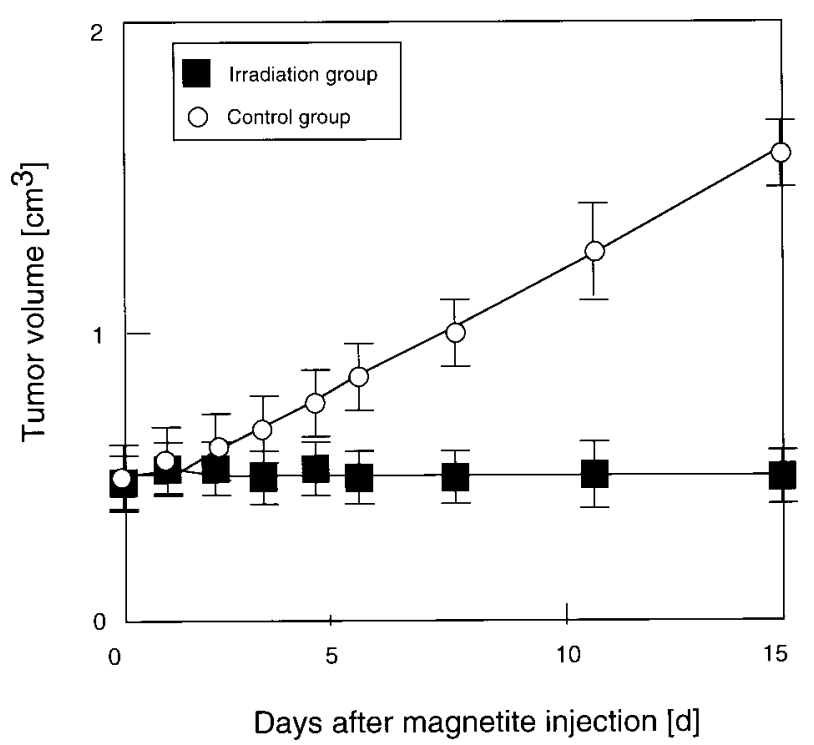

Fig. 8 Time courses of tumor growth. Data points and bars are means and SDs of 5 independent experiments

Fig. 7. Heat taken out from the tumor by blood flow also increases the temperature a little of the other parts of the body, such as the rectum. When the magnetic field irradiation was extended to $30 \mathrm{~min}$, the surface temperature of the tumor increased gradually to $43^{\circ} \mathrm{C}$, whereas, the temperature of the rectum reached $38^{\circ} \mathrm{C}$. As shown in Fig. 5, G22-FMLs were also deposited in the liver and the spleen. However, in both organs removed from the mice after magnetic field irradiation, no necrotic cells were histologically detected in both organ (data not shown). The temperature at the liver or the spleen seems not to have increased to $43^{\circ} \mathrm{C}$ since the G22-FMLs in these organs were low in concentration and existed sporadically, and so the generated heat seems to be removed by the blood flow.

Figure 8 shows the time course of tumor growth after hyperthermia. In the irradiation group, the growth of the tumor was completely suppressed over 2 weeks after irradiation. On the contrary, the tumor volume of the control group without hyperthermia obviously increases. Therefore, it is clear that the tumor is specifically heated by the G22-FMLs and the hyperthermia using the G22-FMLs is effective.

In the previous paper, we reported an induction of antitumor immunity after hyperthermia treatment (Yanase et al., 1998b). In the case of tumor-harboring rats, survived tumor cells could be killed by cytotoxic $\mathrm{T}$ cells induced after the hyperthermia and all tumor cells were completely regressed. However, in the case of a human tumor-harboring nude mouse, the immunity of the host animal can not be expected. Therefore, hyperthermic effect resulted in cytostatic but not cytotoxic.

\section{Conclusion}

In the present paper, we reported that $\mathrm{Fab}^{\prime}$ fragment is more effective for immobilization than the whole molecule of the antibody. The antigenicity of $\mathrm{Fab}^{\prime}$ fragment is lower than that of the whole antibody, so that our method has an advantage in future clinical application.

In summary, we have developed a tumor-specific antibody ( $\mathrm{Fab}^{\prime}$ fragment)-conjugated magnetoliposomes, which can target the glioma cells in vitro and in vivo and are applied efficiently to the hyperthermia of tumor.

\section{Acknowledgment}

This study was partially funded by a Grant-in-Aid for Scientific Research (No. 10145104, 12558106) from the Ministry of Education, Science, Sports and Culture of Japan.

\section{Literature Cited}

Cavaliere, R., E. C. Ciocatto, B. C. Giovanella, C. Heidelburger, R. O. Johnson, M. Margottini, B. Mondovi, B. G. Moricca and A. Rossi-Fanelli; "Selective Heat Sensitivity of Cancer Cells," Cancer, 20, 1351-1381 (1967)

Chan, D. C. F., D. B. Kirpotin and P. A. Bunn, Jr.; "Synthesis and Evaluation of Colloidal Magnetic Iron Oxides for the Site-Specific Radiofrequency-Induced Hyperhtermia of Cancer," J. Magn. Magn. Mater., 122, 374-378 (1993)

Hiraoka, M., Y. Nishimura, Y. Nagata, M. Mitsumori, Y. Okuno, P. Y. Li, M. Abe, M. Takahashi, S. Masunaga, K. Akuta and M. Koishi; "Site-Specific Phase I, II Trials of Hyperthermia at Kyoto University," Int. J. Hyperthermia, 10, 403-410 (1994)

Jordan, A., P. Wust, H. Fähling, W. John, A. Hinz and R. Felix; "Inductive Heating of Ferromagnetic Particles and Magnetic Fluids: Physical Evaluation of Their Potential for Hyperthermia," Int. J. Hyperthermia, 9, 51-68 (1993)

Lyons, B. E., R. H. Britt and J. W. Strohbehn; "Localized Hyperthermia in the Treatment of Malignant Brain Tumor Using an Interstitial Microwave Antenna Array," IEEE Trans. Biomed. Eng., BME-31, 53-62 (1984)

Overgaard, K. and J. Overgaard; "Investigations on the Possibility of a Thermic Tumor Therapy. I. Short-Wave Treatment of a Transplanted Isogous Mouse Mammary Carcinoma," Eur. J. Cancer, 8, 65-78 (1972)

Overgaard, J.; "Effect of Hyperthermia on Malignant Cells in vivo," Cancer, 39, 2637-2646 (1977)

Shinkai, M., M. Matsui and T. Kobayashi; "Heat Properties of Magnetoliposomes for Local Hyperthermia," Jpn. J. Hyperthermic Oncol., 10, 168-177 (1994a)

Shinkai, M., M. Suzuki, S. Iijima and T. Kobayashi; "AntibodyConjugated Magnetoliposomes for Targeting Cancer Cells and Their Application in Hyperthermia," Biotechnol. Appl. Biochem., 21, 125-137 (1994b)

Shinkai, M., M. Yanase, H. Honda, T. Wakabayashi, J. Yoshida and T. Kobayashi; "Intracellular Hyperthermia for Cancer Using Magnetite Cationic Liposome: in vitro Study," Jpn. J. Cancer Res., 87, 1179-1183 (1996)

Suzuki, M., H. Honda, T. Kobayashi, T. Wakabayashi, J. Yoshida and M. Takahashi; "Development of a Target-Directed Magnetic Resonance Contrast Agent Using Monoclonal AntibodyConjugated Magnetic Particles,"Brain Tumor Pathol., 13, 127 132 (1996)

Tazawa, K., T. Nagase, T. Kasagi, M. Maeda, M. Sawadaishi, H. Odagiri, T. Shinbo, Y. Karaki, M. Fujimaki and T. Honda; 
"Intracellular Hyperthermia for the Treatment of Cancer (I): Raising the High Temperature with Exciting Submicron Particles," Hyperthermia in Cancer Therapy, p. 276-277, Mag. Bros. Inc., New York, USA (1986)

Yanase, M., M. Shinkai, H. Honda, T. Wakabayashi, J. Yoshida and T. Kobayashi; "Intracellular Hyperthermia for Cancer Using Magnetite Cationic Liposomes: ex vivo Study," Jpn. J. Cancer Res., 88, 630-632 (1997)

Yanase, M., M. Shinkai, H. Honda, T. Wakabayashi, J. Yoshida and T. Kobayashi; "Intracellular Hyperthermia for Cancer Using Magnetite Cationic Liposomes: a in vivo Study," Jpn. J. Cancer Res., 89, 463-469 (1998a)
Yanase, M., M. Shinkai, H. Honda, T. Wakabayashi, J. Yoshida and T. Kobayashi; "Antitumor Immunity Induction by Intracellular Hyperthermia Using Magnetite Cationic Liposomes," Jpn. J. Cancer Res., 89, 775-782 (1998b)

Yoshida, J., T. Wakabayashi, A. Kito, N. Kageyama, Y. Murata, H. Seo, N. Kojima and K. Yagi; "Clinical Application of Monoclonal Antibodies against Glioma-Associated Antigens," Prog. Exp. Tumor Res., 30, 44-56 (1987)

Yoshida, J., M. Mizuno and K. Yagi; "Secretion of Human $\beta$-Interferon into the Cystic Fluid of Glioma Transfected with the Interferon Gene," J. Clin. Biochem., Nutr., 11, 123-128 (1991) 